\title{
Research on Multimodal Transport of the Experimental Zone of Zhengzhou Airport Comprehensive Economy
}

\author{
Junfeng Guo \\ Department of Economics \\ School of Trade and Business \\ Huanghe Science and Technology College \\ Zhengzhou, Henan, China
}

\begin{abstract}
After the State Council officially approved the "Development plan of the Experimental Zone of Zhengzhou Airport Comprehensive Economy", the Zhengzhou Experimental Zone has become the first zone to carry out the airport economic development as the national strategic task in China, and it assumes the important task to enhance the progress and de velopment of new emerging inland economic zones. To promote the construction of the experimental area, we must take traffic as the starting point to improve the modern integrated transport system, and then we can give full play to the role of the Experimental Zone of Airport Comprehensive Economy. In combination of theoretical analysis and empirical analysis, this paper discussed and demonstrated the development of multimodal transport from three aspects of theoretical research, empirical analysis and countermeasures discussion, and so proposed ideas, guidelines and suggestions on the multimodal transport of the Experimental Zone of Zhengzhou Airport Comprehensive Economy.
\end{abstract}

Keywords-the Experimental Zone of Zhengzhou Airport Comprehen sive Economy; multimodal transport, integrated hub

\section{INTRODUCTION}

Today in the 21st century, the aviation hubs have been greatly developed in the United States, some countries and regions in Europe and Asia, and the ground collection and distribution and transportation network for these hubs will be improved increasingly, and an easy and convenient integrated ground transport system will be constructed, which not only can make good the airport location to some extent and promote the potential of local demand and transit needs, but also help the airline make efficient operation of hub and strengthen the airline in the base. The achievement of the development goal to construct international air cargo hub and domestic integrated aviation hub in Zhengzhou will depend on the development of intermodal transport. Zhengzhou is located in the Central Plains and has convenient transportation, with accessible highways in all directions. Zhengzhou is also known as China's heart of railway transportation, with extremely developed railway transportation. In addition, Xinzheng Airport, as the larger international aviation airport in China, not only lays a strong foundation of transportation for the establishment of the Experimental Zone of Zhengzhou Airport Comprehensive Economy, but also offers more possibilities for the establishment of mu ltimodal transport.

\section{OVER VIEW OF MULTIMODAL TRANSPORT}

Intermodal transport refers to a process that uses two or more (including two) modes of transport (these two or more modes of transport must be connected together), to trans port goods or passengers from the departure to the destination. In this process two or more different transports are closely connected together and to form a coherent transport system, and a multimodal transport contract is signed and a unified single transport rate is used in the whole trip. On this base, the intermodal transport of airport is to introduce two or more modes of transport into the airport and take integrated transport hub in the airport as the core to safely and easily send passengers or cargo to the destination by the way of aviation and rail transport, high-speed railway and other modes, so as to realize the multimodal transport with air passenger transportation as the main.

\section{THE EXISTING PROBLEMS IN THE DEVELOPMENT OF THE EXPERIMENTAL ZONE OF ZHENGZHOU AIRPORT COMPREHENSIVE ECONOMY}

In the multimodal transport of airport, the airport in Europe and other countries is undoubtedly the pioneer and pathfinder. In comparis on with the airports in Europe and other countries, the intermodal transport of airports in our country is still in its infancy. In addition to our capital Beijing and Shanghai airports, other airports are still at their planning and trial stage of multimodal trans port.

The Experimental Zone of Zhengzhou Airport Comprehensive Economy takes the airport as the core. In consideration of its orientation, intermodal transport must also take the airport as the core, to create an integrated airport multimodal transportation hub. Now the multimodal transport of "air + rail + road" is planned as the traffic pattern of the experimental zone, to achieve the minimum 
transport time and maximum efficiency in the airport traffic system. But there are many problems in the practice, for instance, the road traffic in the airports is main ly the single road mode, the overall development level of airport intermodal transport is low, with slow development, and there is a great lack of technical experience, personnel structure and technological research.

\section{A. Lack of linkage among various modes of intermodal transport}

To better promote the development of the experimental zone, we must do well the construction of comprehensive transportation hub of airport, do well air-rail and air-ground intermodal transport, achieve the traffic of seamless linkage, to make passengers or cargo fast or "zero-distance" transfer among plane and train and between bus in the same site, and to make the transportation of goods in a reasonable linkage. Among these, the linkage between air transport and rail transport as well as among air transport and rail transport and highway trans port is the most important.

First, there exists link gap among all modes of transport in geographical conditions. Airport is supported by Zhengzhou Xinzheng International Airport, and the linkage between aviation and other transport means is the most important in the airport multimodal transport. In the airport construction, the linkage among some transport tools is the most intractable for airport multimodal transport, including the linkage between air and land, between air and rail.

Secondly, by the influence of division system, there are different management principals in the construction and management of various trans portation means. In our country, various transports are controlled by different national regulatory authorities, which results the separated government of various transport sectors in the management, without coordinative and harmonious management. At the same time, the separated and distinctive management also causes the link gap among various transport modes.

\section{B. Difficult accounting of unified intermodal transport costs}

The traditional intermodal transport is characterized by the unified transport rates, but the accounting methods of transport costs are different among various transport means. Therefore, on the base of linkage achieved among various transport modes, how to calculate the transportation costs is also one of problems in intermodal transport.

\section{The shortage of multimodal transport infrastructure}

First, the lack of sea approach is an important defect in the construction of Zhengzhou airports.

As an inland city in China, Zhengzhou undoubtedly has quite predominant location, but it also has some disadvantages, that is the inconvenient sea transportation. It is more than 600 kilometers from Zhengzhou to the nearest port, which is a big problem for sea transportation. If we use sea transportation, we must send goods to the sea port first through road, rail or air transport, and then to other sea ports, so the road, rail or air transport will greatly increase the cost of sea transportation.

Besides the sea transportation, from the current construction of Zhengzhou Airport, the air transport, rail transport and road transport become the major three categories of multimodal approach. However, the current domestic infrastructure of multimodal transport is incomplete and relatively poor, and the modern technologies in some compellent transportation has a laggard development, such as containers and freezers transportation. In general, the foundation of transport facilities is poor in Zhengzhou, the overall technical equip ment level is still low, and the support for economy is relatively weak, particularly in the supply of subsequent reserve. There is a certain gap for such a huge project as the construction of intermodal trans port.

\section{Single service of multimodal transport}

In the entire transport chain, each transport mode provides only partial services, but a stable and smooth transit is required among different transport modes of passengers and goods in the construction of multimodal transport. Intermodal service is not just a simple linkage between different transport services, and the lin kage should be able to reflect the core values of integrated, safe, efficient and comfort intermodal services.

TABLE I. COMPARISON OF INTERMODAL SERVICES OF RELATED AIRPORTS

\begin{tabular}{|c|c|c|c|}
\hline Airport & $\begin{array}{c}\text { Air-land } \\
\text { intermodal } \\
\text { transport }\end{array}$ & $\begin{array}{c}\text { Air-sea } \\
\text { inte rmodal } \\
\text { transport }\end{array}$ & $\begin{array}{c}\text { Air-rail } \\
\text { intermodal } \\
\text { transport }\end{array}$ \\
\hline $\begin{array}{c}\text { Xinzheng } \\
\text { Airport }\end{array}$ & $\begin{array}{l}\text { Direct bus } \sqrt{ } \\
\text { Remote check-in } \\
\text { service } \times \\
\text { Season ticket } x\end{array}$ & 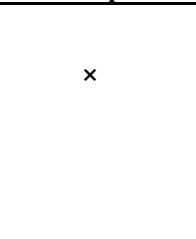 & $\begin{array}{l}\text { Direct high-speed } \\
\text { railx } \\
\text { Remote check-in } \\
\text { servicex } \\
\text { Season ticket } x\end{array}$ \\
\hline $\begin{array}{l}\text { Advanced } \\
\text { airports }\end{array}$ & $\begin{array}{l}\text { Shangha1 } \\
\text { Hongqiao Airport } \\
\text { Direct bus } \sqrt{ } \\
\text { Remote check-in } \\
\text { service } \sqrt{ } \\
\text { Season ticket } \sqrt{ }\end{array}$ & $\begin{array}{l}\text { Hong Kong } \\
\text { Airport } \\
\text { Own pier } \sqrt{ } \\
\text { Remote check- } \\
\text { in service } \sqrt{ } \\
\text { Seasonticket } \sqrt{ } \\
\text { Luggage check } \\
\text { through } \sqrt{ }\end{array}$ & $\begin{array}{l}\text { Frankfurt am Main } \\
\text { Airport } \\
\text { Direct high-speed } \\
\text { rail } \sqrt{ } \\
\text { Remote check-in } \\
\text { service } \sqrt{ } \\
\text { Season ticket } \sqrt{ }\end{array}$ \\
\hline
\end{tabular}

From "Table I", we can see a single service for Zhengzhou airport multimodal transport, and there is a large shortage. There is only intercity bus directly in and out of the airport; the intermodal transport of rail and air transport can $t$ be achieved. The Xinzheng airport, the existing railway stations in Zhengzhou and the Zhengdong high-speed rail station are far, and the linkage is achieved only by the airport bus, and remote check-in service is still blank. 


\section{E. Professionals in shortage}

As a construction project specially approved by the State Council, the Experimental Zone of Zhengzhou Airport Comprehensive Economy is also the first among China's airport projects, so it requires a number special facilities and professionals, but the professionals of airport construction is short in our country currently, the expertise in airport multimodal transport is very little, in addition, the airport mu ltimodal transport has a complex conditions, and thus we are just able to build up our international airport on the base of imitating some success cases in other countries. Laggard domestic construction technology and facilities bring a great challenge for intermodal transport, and the professionals of transportation is the key in the entire airport multimodal transport construction, while such talent is extremely lacking in our country. In addition to these professionals, the talents in management are also indispensable.

\section{THE COUNTERMEASURES AND SUGGEST IONS ONTHE MULTIMODAL TRANSPORT OF EXPERIMENTAL ZONE OF ZHENGZHOU AIRPORT COMPREHENSIVE ECONOMY}

The experimental zone will take the construction of international air cargo hub as the core, to build the threenetwork-combined multimodal transport system of "railway and highway and airport" and create the comprehensive competition advantage in supporting collection and distribution. Currently the mu ltimodal transport construction of the experimental area has got important progress, and the Phase II project of the airport is advancing smoothly, the “米 "-shaped railway construction has achieved a breakthrough and the construction of peripheral road network is accelerated. While, there are also many problems in the entire construction, looking forward to the relevant policy to be issued.

\section{A. Do well the long-term planning for the construction of airport-centered intermodal transport}

Airport construction is an important infrastructure construction that has strong integration, wide involvement and large capital investment. According to the experiences of overseas airport development, we know the governmental intervention in the early overall planning of the airport has an important signification for the airport and the development of regional economy. Therefore, in the construction of intermodal transport, the government should make consideration of airport orientation, regional economic development, environmental protection, demands of airlines and passengers and other factors, to determine the principles, clear the objective, and do well the long-term planning.

In the current planning and design of the experimental zone, the "three vertical and two horizontal" highway network, the "five vertical and six horizontal" trunk road network and the "米"-shaped rail network have formed, but there is not a systematic and overall planning yet. In reference of the experience of domestic and international airport multimodal transport and in combination of the actual conditions of the experimental zone, I think the construction of multimodal transport should follow the below

ideas:

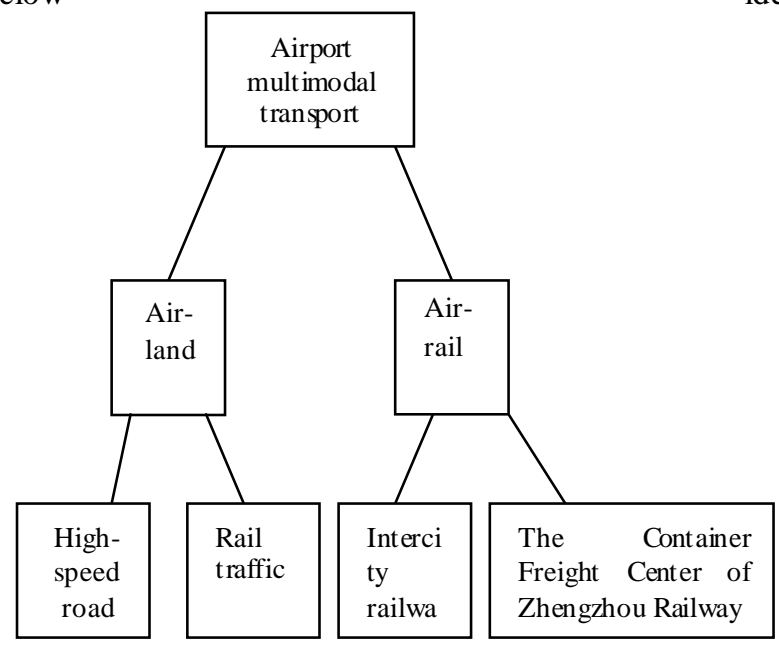

On the one hand, do well air-land intermodal transport to link up the "three vertical and two horizontal" highway network and the "five vertical and six horizontal" trunk road network with the airport and to link up the subway and other rail transports with the airport; on the other hand, do well airrailway transport to the intercity rail and the container freight center of Zhengzhou Railway with the airport. We should plan for the ground transportation network, to form a ground transportation network with high-speed rail, urban rail and highway as the framework and with ordinary trunk line and express way as the supplement and with train, airport bus and urban bus as the important transport mode, by improving the effective linkage of transportation between airport terminals and building rail transit hubs. This seamless linkage of transport modes requires the minimum time and the maximum efficiency in transport tools transit of both goods and passengers, in order to save time and improve operational efficiency.

\section{B. Establish a long-term effective communication mechanism among multiple agencies and multiple sectors}

In the construction and operation of multimodal transport, we should achieve the linkage between the airport and the local government and between the railway and the highway departments and establish a fixed long-term effective communication mechanism, to reach high degree of consensus among all levels of the central and local governments and the related business entities. We should establish a planning and design platform and working mechanis ms of breaking through institutional constraints and linking different sectors, break the boundaries of admin is trative divisions, and build unified construction and development entity. Affected by the division system, currently Zhengzhou airport fails to effectively integrate the various modes of transport. the air-land and air-railway intermodal transport involve all aspects of operation and management, and in the specific operation, we must make innovation and integration of the current ownership model 
separated each other, and then establish a mixed ownership mode and achieve the effective extension of air services through the cross-border integration and mutual shareholding of airlines, airports, railways, highways, urban rails and other relative departments. And we should also set up a leading group above the management departments of various transport modes to coordinate the relationship among different stakeholders. For instance, Frankfurt am Main Airport hub adopts the three-party cooperation and alliance among airport, Lufthansa and German Ministry of Railways, and the three parties jointly develop the air-railway intermodal transport program and the corresponding benefit distribution system, to effectively guarantee the conduction of air-railway intermodal transport.

\section{Establish the market economy intermodal mechanism with airport hub as the core}

Air-land and air-railway intermodal transport involve in all aspects of operation and management, and fundamentally speaking, the focus is to establish a market economy intermodal transport mechanis m with airport hub as the core. To achieve the seamless linkage of various modes of transportation, we should give full play to their respective advantages, effectively expand their services and radiation range, and achieve a win-win situation of multiple parties.

We should establish and improve the supporting system in airport, railway and highway departments, and create excellent air-rail and air-land intermodal transport products together with the airlines. Airlines should consider the high speed and convenience of high-speed rail, mainly launch airrailway intermodal transport products, play a "double high" speed advantage, attract aviation customers, and expand the radiation scope of air services.

\section{Make exploration and innovation, better drive the construction of intermodal transport}

Currently, the experimental area has only just begun its development of multimodal transport, and we must further enhance its planning and construction, for there are many serious problems to be solved. Now it is classified as only the preliminary development stage, and various modes of transport is scattered and decentralized, with a low level; its mechanism and regulations can't meet the development requirements of the experimental zone, with rigid and inflexible management system and development mechanism, to be improved; the high-tech talents are lacking, the policy is not implemented completely, also to be enhanced. Intermodal transport has no obvious advantage, and it can't attract capital investment and introduce talents. All the problems are in urgent need of solution currently, and only when these problems are solved, we can really start the development of intermodal transport and achieve the significance of the experimental area approved. This requires us to really recognize the significance of the establishment of the experimental area, and actively boost and widen the opening up, free our minds, bravely make an attempt, and promote innovation, only by which we can give fresh and strong impetus for the construction of the experimental area.
The multimodal transport construction of the Experimental Zone of Zhengzhou Airport Comprehensive Economy has a important signification for optimizing the layout of air cargo freight in our country, promoting the economic development of airports, driving the coordinative development of new urbanization, industrialization and agricultural modernization in the economic zone of the central plains, and promoting the overall expansion and opening up in the western regions. The construction of the experimental zone is brand new, without experiences for reference, completely depending on our groping progress. Facing the existing problems and unfavorable conditions in the construction, we must dare to free our minds, bravely make exploration and innovation, and so we can make a breakthrough and get development, and make the experimental area lead the development of the economic zone in the central plains.

\section{REFERENCES}

[1] Zhang Zhancang et al. The Construction of the Experimental Zone of Zhengzhou Airport Comprehensive Economy and its Role in Driving the Overall Situation - Summary of the 60th High-level Forum on the Development in Henan [J]. Academic journal (Social Science) 2014 (03) of Henan University of Technology.

[2] Zhang Zhancang, Cai Jianxia. The Study on the Construction and Development of the Experimental Zone of Zhengzhou Airport Comprehensive Economy[J]. Academic journal (Philosophical and Social Sciences), 2013 (04) of Zhengzhou University.

[3] Jiu Jingli. The Bottleneck and Countermeasures of Zhengzhou Airport Economic Development Zone [J]. Management Engineer, 2013 (05).

[4] Yan Guangwei. Study on the Application of International Multimodal Transport and Its Development in Our Country [D]. Tianjin University of Finance and Economics, 2010.

[5] Huang Qiujun .Study on the Intermodal Service Development of X airport [D]. Xiamen University, 2013. 